\title{
Conservatives' Approach to Work: Less Prepared for Future Work Demands?'1
}

\author{
DORIS FAY 2 \\ Justus-Liebig-Universität Giessen \\ Giessen, Germany
}

\author{
MichaEL FRESE \\ University of Amsterdam \\ Amsterdam. The Netherlands
}

\begin{abstract}
This study examined conservatism in the domain of work by relating conservatism to work-related attitudes and personal initiative. Wilson's (1973) concept was used, defining conservatism as rooted in a generalized intolerance of uncertainty. Focusing on the domain of work, it was hypothesized that conservatism should be related to avoiding uncertainty at work, such as responsibility, innovation, change, and challenge, and that conservatives would take less initiative at work. Hypotheses were tested in a sample of 478 participants from former East Germany. Questionnaire and behavior-based interview data were analyzed with structural equation modeling procedures; hypotheses were largely supported. Results are discussed referring to future demands at work. It is concluded that conservatives will have more problems adapting to new requirements that evolve with tomorrow's jobs.
\end{abstract}

Wilson coined the term conservatism for a frequently observed clustering of social attitudes (Wilson, 1973; Wilson \& Patterson, 1968). Being conservative implies supporting pro-establishment politics and militarism, insisting on strict rules and punishment, having a right-wing political orientation, and having a tendency to be ethnocentric and intolerant of minority groups. Furthermore, a

The project Aktives Handeln in einer Umbruchsituation (AHUS; Active Actions in a Radical Change Situation) was supported by the Deutsche Forschungsgemeinschaft (DFG, No. Fr 638/6-6; Principal Investigator Michael Frese). The authors also thank the two firms, Bayerische Hypotheken und Wechsel Bank and Tabacco Reynolds, as well as the Hundertjahre Stiftung of the LudwigMaximilians-University in Munich: They all helped in the beginning of the project. Other members of the project are H. Garst, S. Hilligloh, C. Speier, T. Wagner, and J. Zempel. Students who participaled in the study were C. Dormann, M. Erbe-Heinbokel, J. Grefe, T. Hilburger, M. Kracheletz, W. Kring, K. Leng, K. Plhddemann, V. Rybowiak, A. Soose, A. Tag, A. Weike (Giessen), R. Bamesberger, A. Dehnelt, G. Engstle, M. Fontin, B. Hartmann, J. Haushofer, B. Immler, E. Kahl, M. Eichholz, S. Kemmler, C. Lamberts, R. Lautner, A. Röver, B. Schier, S. Schmider, D. Schweighart, H. Simon, B. Waldhauser, T. Weber, and B. Winkler (Munich). Prior publications on the same sample are Frese, Fay, Hilburger, Leng, and Tag (1997); Frese, Kring, Soose, and Zempel (1996); and Frese and Plüddemann (1993).

${ }^{2}$ Correspondence concerning this article should be addressed to Doris Fay. Department of Psychology, University of Giessen, Otto-Behaghel-Strasse IOF, D-35394 Giessen, Germany. e-mail: doris.fay@psychol.uni-giessen.de. 
conservative has an anti-hedonistic outlook on life; is religiously dogmatic; has a general preference for the conventional, the traditional, and maintenance of the status quo; and is opposed to scientific progress. Wilson explained the co-occurrence of these attitudes by proposing one common basis for them: He suggested that they reflect a "generalized susceptibility to experience threat or anxiety in the face of uncertainty" (Wilson, 1973, p. 259). Similar concepts are authoritarianism (Adorno, Frenkel-Brunswik, Levinson, \& Sandford, 1950) and dogmatism (Rokeach, 1960). For example, Rokeach assumed a general intolerance of ambiguity as the basis of dogmatism, which is much like Wilson's intolerance of uncertainty.

According to Wilson (1973), the term uncertainty refers to all situations that involve innovation, novelty, ambiguity, complexity, risk, and anomie. As these different manifestations of uncertainty are aversive to conservative people, conservatives avoid them. This implies that conservatism is related to attitudes, values, and behaviors that reflect a dislike of uncertainty. Similarly, conservative people try to reduce any kind of uncertainty that they are confronted with or avoid and downgrade it. Wilson assumed that these uncertainty-avoiding, and thus conservative, attitudes and behaviors serve an ego-defensive function. According to Wilson, "They arise as a means of simplifying, ordering, controlling, and rendering more secure, both the external world ... and the internal world" (p. 261).

Several studies that relied on Wilson's (1973) concept of intolerance of uncertainty found that conservatives dislike uncertain art: They prefer familiar pieces of music over unknown pieces (Glasgow \& Cartier, 1985), simple over complex poems (Gillies \& Campbell, 1985), representational over abstract paintings (Wilson, Ausman, \& Mathews, 1973), and plausible over implausible texts (McAllister \& Anderson, 1991). With respect to their cognitive functioning, it appeared that when conservatives were instructed to recall implausible texts, they imported significantly more inferences into their recall protocol. This has been interpreted as an attempt to make the implausible text less ambiguous (McAllister \& Anderson, 1991).

\section{Conservatism and Tomorrow's Workplaces}

In contrast to the extensive research on conservatism and similar concepts, with regard to their relationship to societal attitudes, beliefs, values, and attributions, investigations of conservatism in the domain of work is scarce. One of the few studies from this area found that conservatives assign more importance to job security and less importance to variety at work (Atieh, Brief, \& Vollrath, 1987). In this article, we explore further the significance of conservatism in the domain of work. Considering that tomorrow's workplaces will undergo a rapid sequence of changes, we think that a personality variable such as conservatism needs to be studied. 
Trends of how jobs will change imply that technology, knowledge, and production methods will become obsolete more quickly (Howard, 1995), which will impose high demands on working people's flexibility and adaptability. Lifelong learning will be critical if one wants to keep up with the changes (Hall \& Mirvis, 1995). As global competition becomes stronger, a faster rate of innovation is required. Trends in organizational reorganizations involve decentralization, reduced supervision, less hierarchy, and more job discretion for the individual. Changing the typical top-down hierarchy in an organization will lead to reductions in structure which make willingness to take responsibility as well as independent and self-started actions increasingly important (Lawler, 1994). Moreover, career planning must be done more actively. The traditional working biography - to be trained and to stay in one profession for one's entire working life, and most likely in the very same organization-becomes increasingly unlikely. In some countries, even complete economic branches are becoming superfluous, and at the same time completely new jobs emerge. Thus, actively thinking about the future and planning one's career becomes more important. In light of these trends, which bear many characteristics of the uncertainty that is avoided by conservatives, we think that conservatism is an important factor in understanding relevant phenomena at work.

\section{Conservatism in the Specific Situation of East Germany}

We assume that a phenomenon such as intolerance of uncertainty should be studied in a situation of elevated uncertainty because conservatism and its related attitudes should be more salient, and thereby better observable, in an uncertain condition than in a highly predictable, clear, and stable environment. Such a situation of high uncertainty is particularly prominent in countries undergoing the transition from bureaucratic socialism to capitalism. Here, rapid changes inside and outside work prevail with new demands and exceptionally high change requirements. For this reason, in this article we will concentrate on data from East Germany.

Tremendous economic modifications began after the revolution and the subsequent reunification of Germany in 1990. Until then, East German industry still relied heavily on mass production, and the service sector was less developed than in West Germany (Kieler Diskussionsbeiträge, 1991). Since then, East Germany has had to change its products, production processes, marketing orientations, and ownership of companies (Wittke, Voskamp, \& Bluhm, 1993).

\section{Theoretical Framework of Conservatism}

Recent research on conservatism was conducted primarily within a cognitive framework, using measures that focus on intra-individual processes, such as 
cognitive style (Tetlock, 1984; Tetlock, Bernzweig, \& Gallant, 1985) and need for cognition (Waller, 1993). In general, we agree with this cognitive approach. However, we found Wilson's (1973) motivational approach to conservatism in terms of uncertainty avoidance most useful for our specific research question, which looks primarily at attitudes and behavior toward unpredictability and uncertainty in the work domain. Therefore, we use a motivational framework, employing a general measure of conservatism with a generic level of decomposition.

\section{Hypotheses}

Conservatism is expected to have a positive relationship with work-related attitudes and behaviors expressing the avoidance of uncertainty at work, specifically the avoidance of change and risk at work.

\section{Conservatism and Change Orientation}

Uncertainty at work increases when changes take place, forcing an individual to adapt to new demands, to acquire new knowledge, or to cope with modifications in the social structure. Conservatives, however, prefer playing it safe, doing things the way they "have always been done" by adhering to "dear" routines. Therefore, they should be less ready to change at work (Frese \& Plüddemann, 1993). Moreover, they should feel more threatened by the introduction of new technology.

Hypothesis 1 . It is predicted that there is a negative relationship between conservatism and readiness to change at work and a positive relationship to the rejection of new technology.

\section{Conservatism, Innovation, and Personal Initiative}

At work, changes are not only imposed onto people by superiors, but they may also come about by employees introducing changes themselves. We suggest that the side effects of changes-various manifestations of uncertainty-are experienced negatively by conservatives, irrespective of who initiates the change. Conservatives are assumed to regard changes as highly unpleasant, even if they themselves should start them.

Hypothesis 2. A negative relationship is expected between work innovation and conservatism.

Personal initiative is defined as extra-role action that goes beyond what is formally required in a given job (for a more detailed discussion of the concept, see Frese, Fay, Hilburger, Leng, \& Tag, 1997; and Frese, Kring, Soose, \& Zempel, 
1996). Personal initiative should also be negatively related to conservatism since initiative implies that one changes one's routines and does things out of the ordinary. An example might illustrate this. An employee of a purchasing department finds the organization of the filing system inefficient because not everyone has access to the files when needed. Therefore, she suggests to her colleagues to reorganize the filing system in order to make relevant information immediately retrievable to everyone. With this suggestion she puts herself into a situation of uncertainty: She does not know how her colleagues are going to react, whether her supervisor is going to sanction her actions, or whether her idea will be successfully realized. Thus, personal initiative implies a certain degree of uncertainty because the consequences of initiative on the social and work environment are unpredictable.

Hypothesis 3. It is predicted that there is a negative relationship between conservatism and personal initiative.

Conservatism and the Desire for Control, for Hierarchical Structure, and for Self-Actualization

Control-being able to make relevant decisions in one's job-has turned out to be a positive factor for stress and taking initiative. However, control at work usually implies having more responsibility. Organizations are changing institutions in a changing environment, which makes the work situation usually too complex to predict perfectly. Thus, responsibility goes hand in hand with a certain degree of uncertainty and provokes anxiety for conservatives. Therefore, conservatives should prefer receiving orders and instructions that do not leave much room for decision making that implies personal responsibility.

Hypothesis $4 a$. It is expected that conservatism is positively related to rejecting control and negatively to aspirations in decision making.

A hierarchy is the more conventional and familiar structure of an organization, and it reduces the number of unstructured situations. Therefore, conservatives have an interest in authoritarian structures with clear orders. Preference for a hierarchical structure within an organization implies that there should be a higher preference for a clear, but unequal distribution of power and rights. This is a concept akin to power distance (Hofstede, 1991), used here as a within-culture individual-difference measure.

Hypothesis $4 b$. A positive relationship is expected between conservatism and power distance. 
Self-actualization implies that one pushes the borders of one's abilities and strives for personal growth, development, and accomplishment. This requires that one exerts oneself to new situations and challenges. Conservatives avoid these situations and should accordingly have a lower degree of higher order need strength.

Hypothesis $4 c$. It is predicted that conservatism is negatively related to higher-order need strength.

\section{Conservatism and Attitudes Toward Women's Employment}

Two opposing hypotheses concerning conservative's attitudes toward working women can be put forward. The first one proposes that conservatives are against female rights, including their right to hold jobs. Wilson and Patterson (1968) included items on women in the work force (working mothers and female judges) in their conservatism scale. We will call the hypothesis that conservatives reject a woman's right to hold a job the Western model of conservatism.

However, the content of conservatism cannot be employed without careful consideration of history and culture (Rokeach, 1973), as orientation on traditions and conventionalism are part of the conservative syndrome. East German attitudes toward women may be different because East Germans were socialized in a society that traditionally gave jobs to women. In East Germany, $91 \%$ of the women held jobs, a much higher percentage than in Western countries (e.g., in West Germany, the respective number was 51\%; Der Spiegel, 1991). This implies that East German conservatives might advocate a woman's right to employment (called the East German model of conservatism). However, McFarland, Ageyev, and Abalakina-Paap (1992) found that the content of attitudes changed between 1989 and 1992: In the former Soviet Union, the correlation between authoritarianism and support for Marxist-Leninist ideology decreased in this period. Therefore, we do not have sufficient information to decide in favor of either hypothesis.

Hypothesis 5. It is predicted that conservatism is positively related to rejecting a woman's right to work, according to the Western model of conservatism; and negatively related to rejecting a woman's right to work, according to the East German model of conservatism.

\section{Conservatism and Attitudes Toward Errors}

The appearance of errors is more or less an everyday occurrence, which is-because of their possible negative consequences-generally experienced as stressful (Rybowiak, Garst, Frese, \& Batinic, 1999). Errors are associated with much uncertainty: In order to correct an error, one is often forced to depart from 
routine action to find a solution; sometimes it is unclear how or whether one can correct the error, and sometimes unexpected long-term effects appear. Conservatives are thought to experience this as highly aversive and threatening. Therefore, they should put more emphasis on avoiding errors.

Hypothesis 6. Conservatism is expected to be negatively related to error risk taking.

\section{Third Variables}

Three kinds of third variables could produce spurious relationships between conservatism, work-related attitudes, and personal initiative, and should therefore be controlled for. First, gender, age, education, and socioeconomic status (SES) can be confounding third variables. Conservatism has been found to be significantly related to gender and age, with females ${ }^{3}$ as well as older people scoring higher on conservatism (Feather, 1977; Truett, 1993; Wilson, 1973). Furthermore, people with a low level of education (Bahr \& Chadwick, 1974; Ray \& Wilson, 1976) and from low social class (Eysenck, 1971; Kohn \& Schooler, 1983 ) tend to be more conservative. Similarly, there is evidence that work-related attitudes and personal initiative are related to the same variables. For example, Kohn and Schooler reported a significant relationship between SES and a participant's stance toward change, with participants from a higher social class being more receptive to changes in general. Likewise, study participants with higher SES exhibited more personal initiative (Frese et al., 1996). This means that gender, age, education, and SES can have an effect on conservatism, work-related attitudes, and personal initiative, and need thus be controlled for.

Second, the negative affectivity personality variable could be a third variable. In research on work stress and strain, negative affectivity has been discussed as a variable that inflates self-reported stressor-strain relationships (Schaubroeck, Ganster, \& Fox, 1992). Individuals with higher negative affectivity are more likely to experience aversive mood states, which are assumed to cause a negative interpretation of stimuli, such as stressors and strain. Negative affectivity can play a similar role in the relationship between conservatism and work-related attitudes and personal initiative: Individuals with a higher tendency to feel distressed may have a stronger urge for stability. This urge results in generally conservative opinions and in the preference for a stable work environment in which one need not adapt to new situations. Thus, negative affectivity must also be controlled for.

Lastly, factors external to the person are a type of third variable. Uncertainty and change requirements are and have been high in East Germany, especially in

${ }^{3}$ However, we do not think that women are more conservative than men. The differences found can probably be attributed to a lower educational level on the part of the women. 
the domain of work. Environmental uncertainty may evoke a stronger need for stability. A reaction to this could be a "conservative shift," affecting all discussed attitudes and behaviors. Such a phenomenon was shown for authoritarianism, which increased with threatening societal conditions (Sales, 1973). In this study, we want to focus on the dispositional part of conservatism and seek therefore to exclude transient, externally caused effects. Therefore, uncertainty and change requirements will be controlled for.

\section{Method}

\section{Participants and Procedures}

Study participants were respondents of a longitudinal and representative study, carried out in Dresden, the capital of Saxonia, in former East Germany (Frese et al., 1996, 1997). The study reported here is based on the fifth wave, as we have measured conservatism only at that point. The fifth wave took place in 1993, with 478 participants. Age ranged from 20 to 67 years, with a mean age of 43 years $(S D=11.5$ years $)$; $49.3 \%$ of the sample were female. Participants' employment level was assigned to one of three classes, as an index of SES: $38.5 \%$ of participants were unskilled, semiskilled, and skilled workers; $22.8 \%$ were primarily white-collar workers, such as lower professionals and administrative workers; and $39.6 \%$ were higher professionals and managers. Of all participants, $30 \%$ had a university degree. In $1993,80.2 \%$ of the participants were employed, $7.3 \%$ were unemployed, $10 \%$ were retired (or early retired), and the remainder were housewives or were taking maternity leave.

Participants took part in a structured interview in which personal initiative was assessed. After this, they were given a questionnaire which they filled out at their leisure and which was picked up later by an interviewer.

\section{Measures}

Both interview and questionnaire measures were taken. Before we tested the hypotheses, we analyzed all scales with LISREL 8 . The measurement models were improved in this first step, and some items with low reliabilities were omitted. 4 The number of items that were used for each scale is reported here. If not stated otherwise, a 5-point Likert format was used for responses. All items were in German.

Measures of conservatism. Our measure of conservatism was inspired by the conservatism scale of Schiebel, Riemann, and Mummendey (1984), which is the German version of the extensively used Wilson-Patterson Conservatism scale ( $\mathrm{C}$

\footnotetext{
${ }^{4}$ The goodness of fit indexes for each measurement model and the specific items contributing to each construct can be obtained from the first author.
} 
scale; Wilson \& Patterson, 1968). For several reasons, we could not adopt the German $\mathrm{C}$ scale in our sample unchanged. In the $\mathrm{C}$ scale, four major facets of conservative attitudes have been identified with factor analysis: (a) preference for authoritarian upbringing and political conservatism, (b) rejection of women's liberation, (c) rejection of foreigners, and (d) rejection of sexual freedom. The first factor would not have been applicable unchanged in our sample, as some items referred to right-wing political orientation. This is not a useful measure of conservatism in East European countries. Instead, assessing Marxist or socialist orientation is more appropriate (cf. McFarland et al., 1992). ${ }^{5}$ The second factor, rejection of women's liberation, also had its limitations, as women's societal role had, in East Germany, been different from the countries where the scale was developed. The content of the last factor, rejection of sexual freedom, would have appeared too intimate in a questionnaire primarily oriented toward work.

Relying on the content of the first and third factors, conservatism was assessed by measuring authoritarianism and hostility toward foreigners. The former is, according to Ray (1973), a good representation of conservatism: "Neither conceptually nor empirically does there appear to be any ground for distinguishing authoritarianism and conservatism except that the former may be regarded as a somewhat more particular case of the latter" (p. 33). The Authoritarianism scale (Lederer, 1983) is a well-validated scale used frequently in Germany, measuring a preference for strong authority, strict rules, and punishment. A sample item is "We should be grateful to our leaders for telling us what to do and how to do it." For reasons of economy, we took a selection of items with high reliabilities, and a measurement model with five items showed good results. Hostility toward foreigners was measured with a newly developed, four-item scale, covering the issue of whether foreigners should be allowed to work in Germany (e.g., "I think we Germans should stay among ourselves, and--as in Germany unemployment increases-foreigners should look for work in their own countries"), and overt hostility toward foreigners ("I have an understanding for people becoming violent against foreigners").

Work-related attitudes and personal initiative. The Readiness to Change Scale measures whether the respondent wants to have changes in his or her job. A sample item is "I like a job that changes often and quickly" (Frese \& Plüddemann, 1993; 4 items). The rejection of new technology measure captures opposing the application of computers because of their negative effects on work and society (Frese, 1984; 6 items). Items were assessed only up to the third measurement wave of the longitudinal study; these data were collected in 1991.

${ }^{5}$ The ideologue hypothesis on conservatism assumes that the actual content of extreme beliefs is not critical. According to Tetlock et al. (1985), "differences in the content of left-wing and right-wing political belief systems should not be allowed to obscure basic cognitive stylistic similarities between the two groups" (p. 1228). Tetlock (1984) found empirical evidence for the similarity of the cognitive functioning of left and right extremes. 
Work innovation was measured with a scale by Patchen ( $1965 ; 5$ items). The best measurement model was obtained by dividing this scale into two constructs, describing interest in innovation and reports on attempted and executed innovations. The Power Distance Scale measures a preference for inequality at work by conceding more privileges, status symbols, and rights to supervisors (e.g., "Supervisors should have a possibility to eat in their own cafeteria"). This scale is modeled after the definition of power distance by Hofstede (1991; 4 items). The Control Rejection Scale measures the degree to which the respondent refuses control because of the possible negative consequences of the responsibility involved (e.g., "I do only what I am told to. Then nobody can reproach me for anything"; Frese et al., 1996; 7 items). Aspirations for participation is an index consisting of two items developed for this study: "I want to be consulted when my workplace is changed," and "I find any type of participation of employees superfluous" (reverse-scored). Higher-order need strength was measured with four items from Warr, Cook, and Wall's (1979) scale.

Rejection of women's rights to a job is a new scale, measuring whether women should be as entitled to hold jobs as are men (e.g., "Vacant jobs should preferably be given to men"; 4 items). Error risk taking was taken from Rybowiak et al. (1999); it measures whether errors should be accepted in order to reach one's goals (3 items).

Personal initiative was measured using the following five scales assessed in the structured interview (described in more detail by Frese et al., 1996, 1997): General initiative at work was based on several specific extra-role activities at work (e.g., submitting a suggestion for improving work). Education initiative asked for ongoing and past job-related education initiative. Overcoming barriers measured the persistence that one shows in the face of barriers. Participants were confronted with a problem scenario and asked to develop a solution to it. After solving the problem, they were presented with barriers and then asked to develop further solutions to the problem. Active approach was an interview rating of whether the problem-solving strategies used in overcoming barriers showed an active orientation in contrast to delegating the required action to someone else. Interviewer evaluation was the interviewer's subjective impression of how initiating, action-oriented, plan-oriented, and goal-oriented the participant was.

Factor analyses of previous research with different East German and West German samples has shown that these five specific measures of personal initiative can be aggregated to produce one general measure of personal initiative (Frese et al., 1997). This general measure of personal initiative is primarily behavior based, and it shows good external validity. For example, high-initiative participants find a job faster when they become unemployed, and self-employed people show higher measures of initiative (Frese et al., 1997). In the present study, we use the five measures of personal initiative described in the previous paragraph (transformed to $z$ scores) as indicator variables to model a general latent construct of personal initiative. 
For the analysis presented here, we added a questionnaire-based initiative scale, which measures long-range and proactive plans with respect to one's career. This is-especially for East Germany, where most people will have to eventually change jobs-an important area in which one can show initiative. It is negatively worded and is therefore called passivity (Frese et al., 1997; 7 items).

Third variables. Age, gender, and education (a dichotomous item, depending on whether or not the participant had a university degree) were measured with the questionnaire. Participants' employment level, used to make an index of SES, was ascertained in the interview. Negative affectivity was assessed with the list of negative feelings and emotions from the Positive and Negative Affect Schedule (PANAS; Watson, Clark, \& Tellegen, 1988; 10 items).

Uncertainty and change requirements at work were assessed by three different job characteristics. Uncertainty at work measures how often a participant receives unclear and ambiguous orders, and other aspects of unpredictability (e.g., "How often do you get contradictory orders from different supervisors?"; Zapf, 1991; 5 items). Job Uncertainty is a newly developed scale capturing the perceived likelihood of losing one's job, and the prospects of finding a new one (e.g., "Do you expect to become unemployed?"; 4 items). An index of environmental uncertainty was developed: Indicators of major changes at work reported in the current and previous measurement waves were added (e.g., acquisition of new machines, company was taken over by a West German enterprise).

\section{Results}

\section{Overview}

We tested all hypotheses with LISREL 8, using the two-step model-building approach suggested by Anderson and Gerbing (1988). They recommend testing the measurement model before examining the hypothesized structural linkages. Accordingly, we first analyzed a measurement model that included 14 latent constructs representing conservatism, work-related attitudes, and personal initiative in order to test whether the latent constructs were sufficiently different from each other. Second, we analyzed the hypothesized relationships between conservatism and work-related attitudes and personal initiative with the structural modeling approach. We carried out tests to see whether conservatism was significantly related to each work-related attitude and to personal initiative when controlling for third variables.

Following the suggestion of Hoyle and Panter (1995), several goodness-of-fit indexes (GFIs) are reported. The chi-square fit index indicates a good model fit if the chi square is not significant. Here, the main significance of the chi square is that it allows the comparison of different models to determine which matches the observed data better (Bollen's, 1989, chi-square difference test for nested models). The root mean square error of approximation (RMSEA) is good when it is 
not higher than .08 (Browne \& Cudeck, 1993). The standardized root mean square residual (SRMR) index is acceptable if it is .05 and lower. The adjusted GFI (AGFI) and the comparative fit index (CFI) indicate an acceptable model when they are .90 or higher.

The following strategy for treatment of missing data was used: The covariance matrix was computed with pairwise deletion of cases. As the number of missing data differed in all variables, the median of the effective pairwise sample size was calculated for each analysis in order to estimate the sample sizes.

Testing the Measurement Model of Conservatism. Work-Related Attitudes, and Initiative

First, a measurement model of the conservatism scales, the work-related attitudes, and personal initiative was analyzed using the maximum-likelihood estimation. The goodness-of-fit measures indicated a good model fit: RMSEA = $.035, \mathrm{SRMR}=.054, \mathrm{AGFI}=.82, \mathrm{CFI}=.90$. The chi square was significant, $\chi^{2}(1561, N=450)=2,414.05(p=.00)$, and the AGFI was a little low, but all other measures looked good. Table 1 presents the correlations of all latent constructs. The two latent constructs representing conservatism, authoritarianism, and rejection of foreigners were significantly correlated $(\phi=.55)$, indicating that the constructs had something in common, but were sufficiently different to keep them separate. Except for two correlations, both conservatism measures were significantly related to the work-related attitudes and to personal initiative. Correlations were always in the predicted direction.

Two correlations of .70 were found, suggesting that the respective constructs (higher-order need strength, readiness to change at work, and interest in work innovation) probably did not measure different concepts. A second measurement model was analyzed in which the indicator variables of the three constructs loaded on one latent construct $(\mathrm{RMSEA}=.040, \mathrm{SRMR}=.059, \mathrm{AGFI}=.80$, $\mathrm{CFI}=.87), \chi^{2}(1586, N=450)=2,709.98, p=0.0$. Comparing this model to the first model with the chi-square difference test showed that the first model described the data significantly better, $\Delta \chi^{2}(25, N=450)=295.93, p<.001$. Therefore, the latent constructs of higher-order need strength, readiness to change at work, and interest in work innovation were kept separate.

\section{Analyzing Structural Relationships}

In testing the hypotheses, we analyzed whether conservatism was significantly related to the work-related attitudes and to personal initiative when controlling for the third variables. This was done by comparing two structural models. The first model proposed that the common variance in conservatism on the one hand and work-related attitude and personal initiative on the other (cf. Table 1) could be fully explained by the third variables. This model was called 


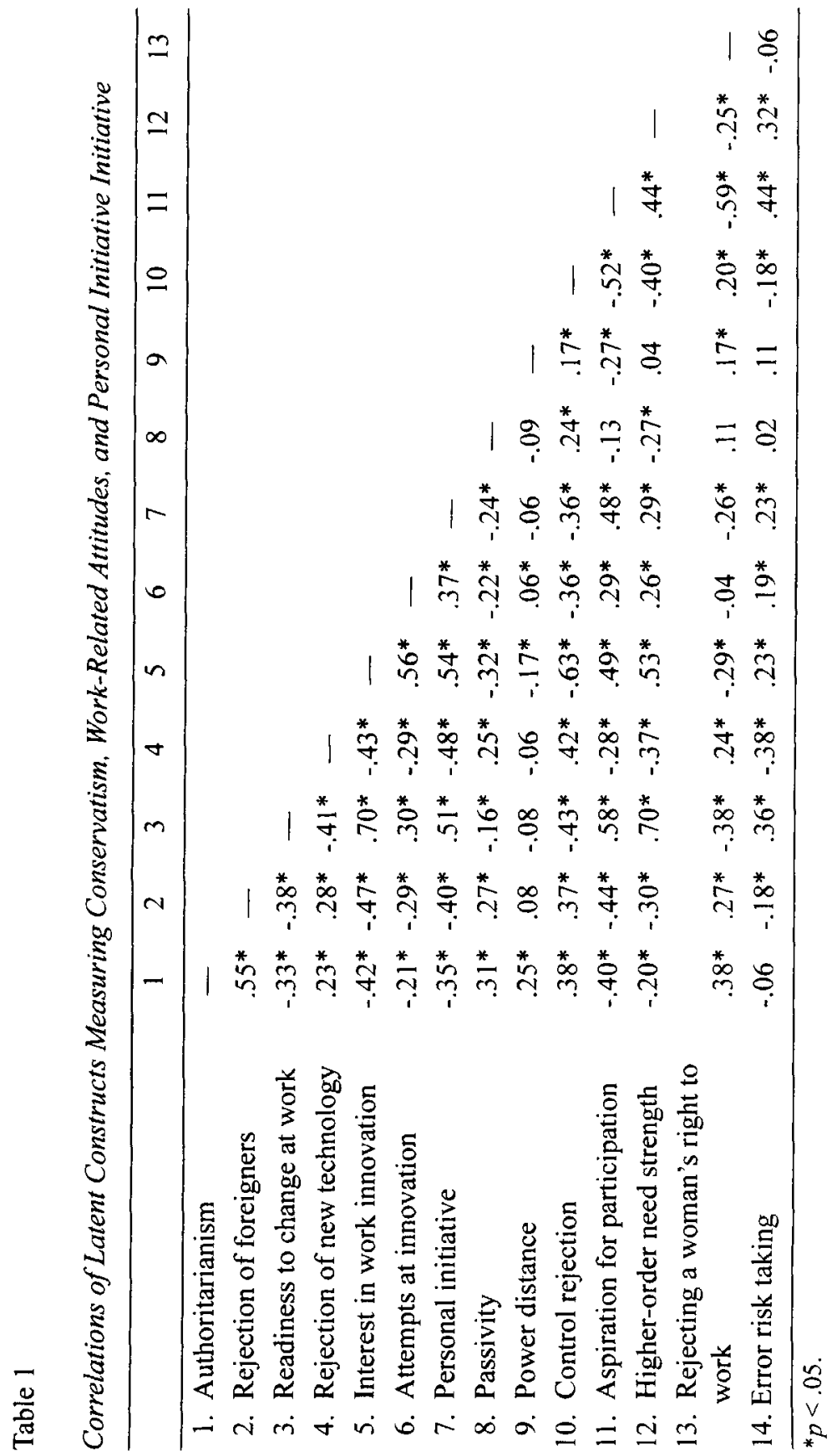




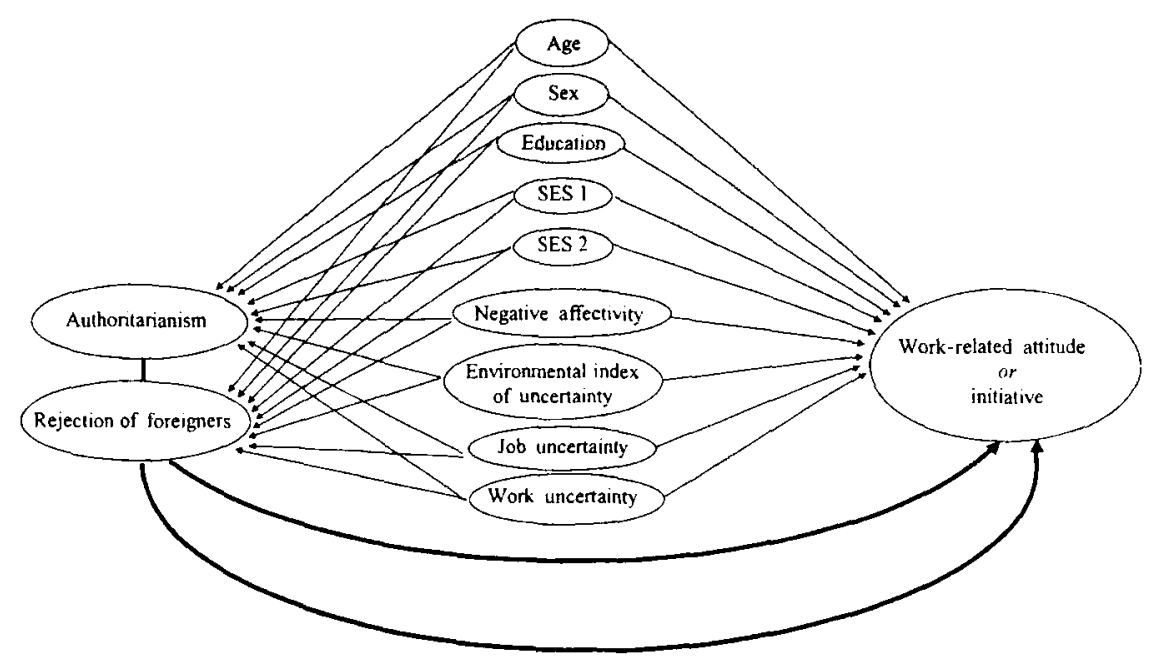

Figure 1. Direct-effect model.

the spuriousness model. It is equivalent to the model depicted in Figure 1, without the two direct paths (boldface) between authoritarianism/rejection of foreigners and work-related attitudes/personal initiative.

The second model proposed that the common variance of conservatism and work-related attitudes and personal initiative cannot be fully explained by the third variables. According to this model, conservatism has a direct effect on work-related attitudes and on personal initiative; hence, it was called the directeffect model (Figure 1). The relationship between conservatism and work-related attitudes and personal initiative was modeled as causal paths from conservatism to work-related attitudes and to personal initiative; therefore, we will refer to the work-related attitudes and to personal initiative as dependent variables. The direct-effect model tested whether there was a significant effect of conservatism on the dependent variables when partialling out the third variables. Both models differed in that the coefficients of the causal paths relating conservatism to the dependent variables were freely estimated in the direct-effect model and were fixed to zero in the spuriousness model.

Each model was analyzed for each dependent variable separately, because including all dependent variables in one model would comprise about 60 indicator variables, which would have been too unreliable with only 478 participants. SES was an ordinal item with three levels; it was thus recoded as two dummy variables. All other third variables were represented by the scale mean as a single indicator variable. The reliabilities of the scales (Cronbach's alpha) were used to fix the error variance of the indicator variable (negative affectivity, $\alpha=.83$; environmental uncertainty, $\alpha=.65$; job uncertainty, $\alpha=.52$; uncertainty at work, $\alpha=.67$ ). 
Table 2 presents the goodness-of-fit measures for the spuriousness model, the direct-effect model, and the results of the chi-square difference test, with which the models were compared. The goodness-of-fit measures were moderate to very good for both models; they were, in general, better for the direct-effect model. The chisquare difference test indicated that the direct-effect model fit the data in most analyses significantly better than did the spuriousness model. This means that the common variance in conservatism and the dependent variables was better explained by a model that allowed a direct relationship between the variables, in comparison to a model that attributed the common variance singularly to the third variables. Furthermore, the squared multiple correlations (degree of explained variance) of the dependent variables were always higher in the direct-effect model. Exceptions to this were rejection of new technology and error risk taking.

Table 3 contains standardized betas and the corresponding $t$ values of the direct effect of conservatism on the dependent variables (cf. Figure 1, direct paths in boldface). For those dependent variables for which the direct-effect model fit the data better, at least one of the paths from conservatism to the dependent variable was significant. ${ }^{6}$ The beta was always in the predicted direction. We found support for Hypothesis 1 , as conservatism was negatively related to readiness to change at work. There was no support for the expected positive relationship with rejection of new technology. Hypothesis 2 suggested a negative relationship between conservatism and work innovation, which proved to be correct. As predicted in Hypothesis 3, conservatism was negatively related to personal initiative and positively to passivity. Hypothesis 4 a predicted conservatism to be positively related to rejecting control and negatively to aspirations for participation; Hypothesis $4 \mathrm{~b}$ suggested a positive relationship with power distance; Hypothesis $4 c$ proposed a negative relationship of conservatism with higher-order need strength; all predictions were supported. With regard to the issue of how conservatism is related to attitudes toward a woman's right to work (Hypothesis 5), the data supported the Western model of conservatism: East German conservatives rejected a woman's right to work. Hypothesis 6 , on the negative relationship between conservatism and error risk taking, was not confirmed.

The third variables had strong effects on conservatism and on the dependent variables. They explained $30 \%$ of the variance in authoritarianism, and $19 \%$ of the variance in rejection of foreigners. Higher levels of SES and of education were associated with lower levels of authoritarianism and rejection of foreigners; age was positively related to authoritarianism, and females scored lower on rejection of foreigners. Negative affectivity was positively related to both conservatism measures. Of the variables measuring uncertainty at work, only job

6Because of high intercorrelation of the two conservatism constructs, sometimes only one conservatism indicator was significant. However, models in which the significant path was set to zero showed that the path of the other conservatism indicator became highly significant. 


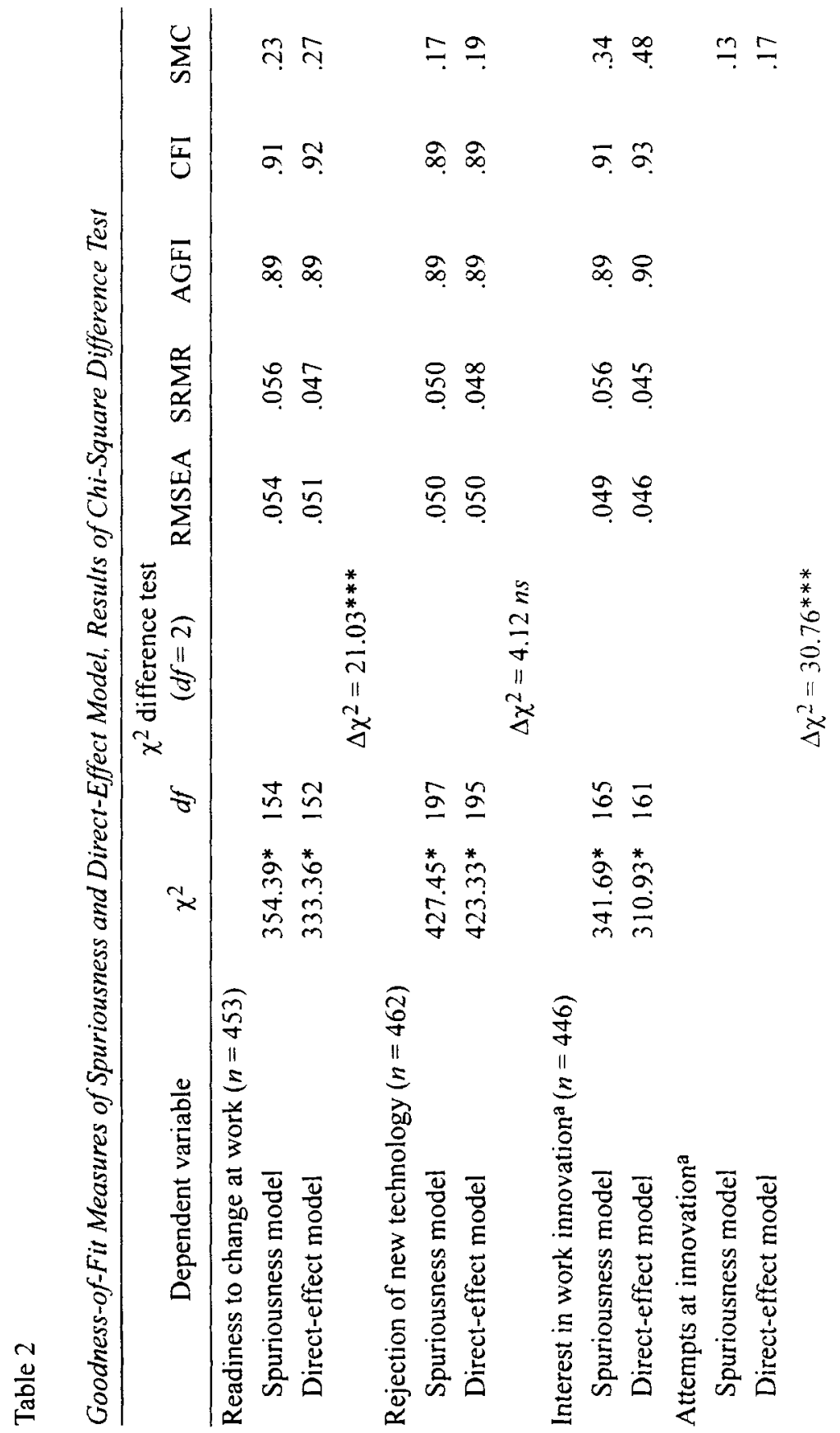




\begin{tabular}{|c|c|c|c|c|}
\hline సి ఢి & $\overline{\mathrm{T}} \overline{\mathrm{m}}$ & $=?$ & त्र & $\approx$ \\
\hline$\infty$. & 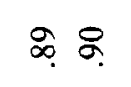 & $2 \%$ & $8 \%$ & $8 \bar{\sigma}$ \\
\hline$\overbrace{\substack{\infty \\
\infty}}^{\infty}$ & $\infty_{\infty}^{\infty}$ & $8 \%$ & $\hat{\infty}_{\infty}^{\infty}$ & के \\
\hline$\ddot{g}$ & $\bar{g}$ of & 옹 웅 & 苧导 & 药 \\
\hline है : & 离 & 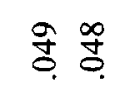 & 乫 & ơ \\
\hline
\end{tabular}
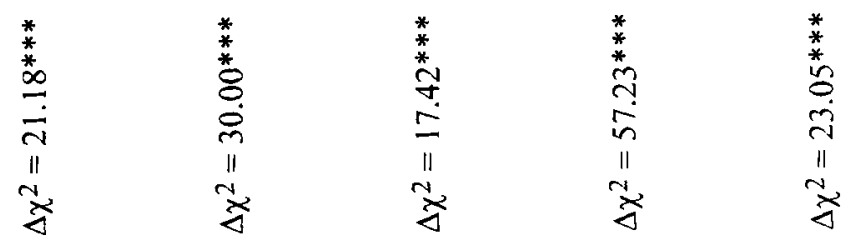

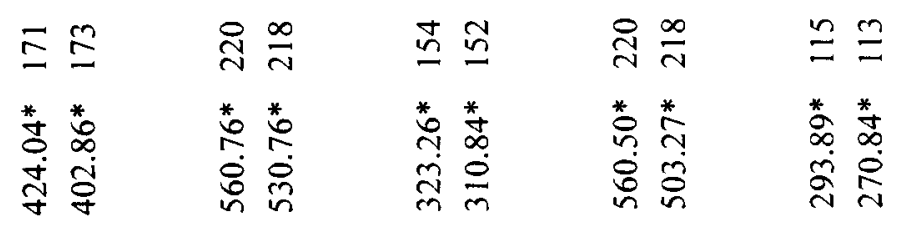

守

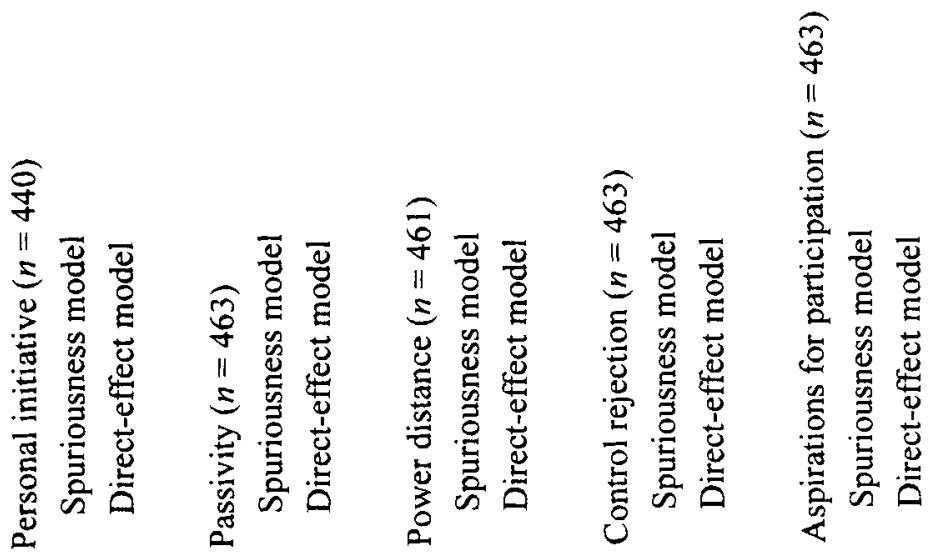




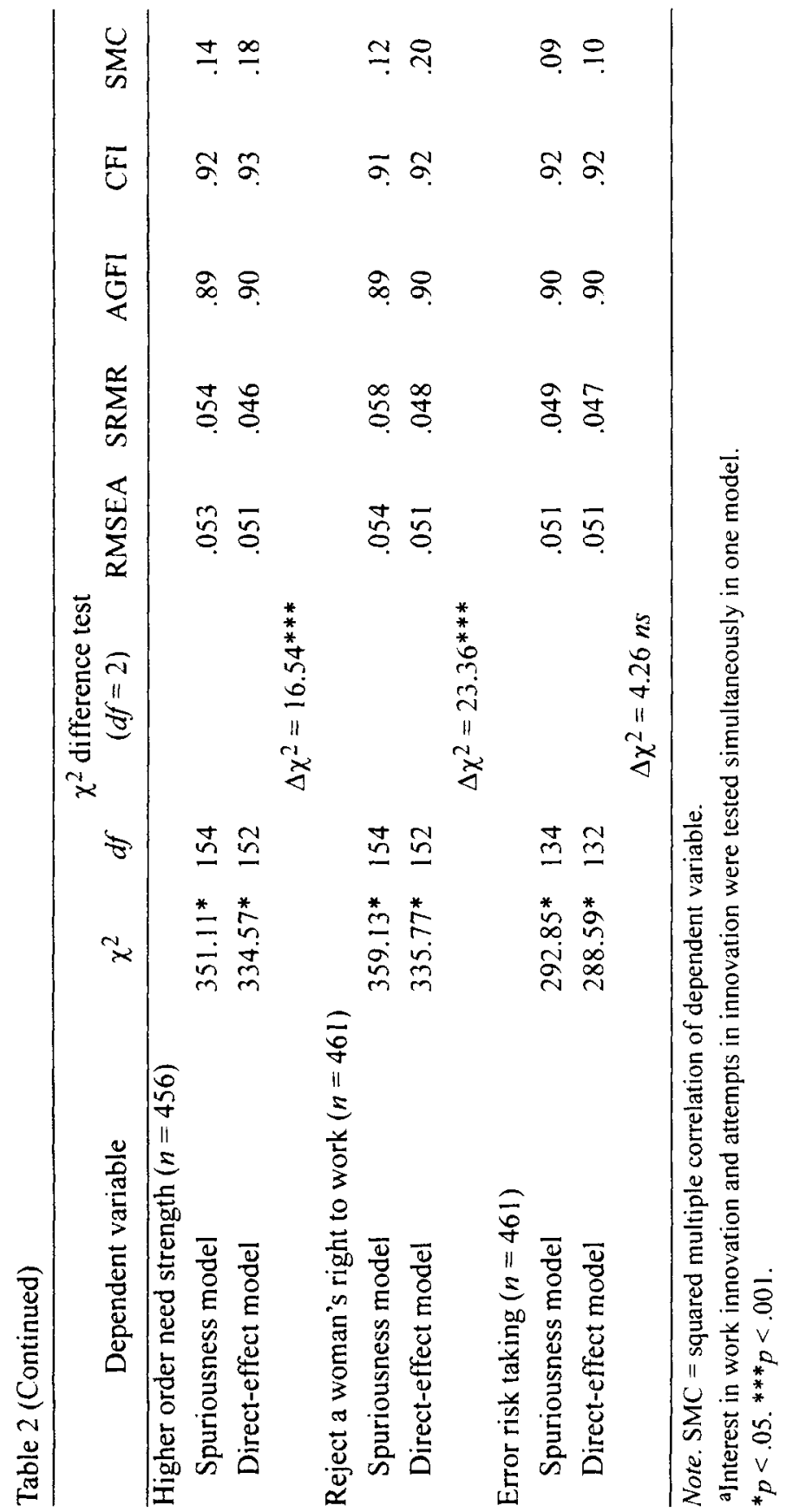


Table 3

Standardized Beta and Corresponding $\mathrm{t}$ Value of Path from Authoritarianism and Rejection of Foreigners to Dependent Variable in Direct-Effect Model

\begin{tabular}{|c|c|c|}
\hline Dependent variable & Standard $\beta$ & $t$ value \\
\hline \multicolumn{3}{|l|}{ Readiness to change at work } \\
\hline Authoritarianism & -0.09 & -0.92 \\
\hline Rejection of foreigners & -0.21 & $-2.55^{*}$ \\
\hline \multicolumn{3}{|l|}{ Rejection of new technology } \\
\hline Authoritarianism & 0.12 & 1.08 \\
\hline Rejection of foreigners & 0.04 & 0.48 \\
\hline \multicolumn{3}{|l|}{ Interest in work innovation ${ }^{a}$} \\
\hline Authoritarianism & -0.36 & $-2.36^{*}$ \\
\hline Rejection of foreigners & -0.15 & -1.24 \\
\hline \multicolumn{3}{|l|}{ Attempts at innovation ${ }^{a}$} \\
\hline Authoritarianism & -0.14 & -1.30 \\
\hline Rejection of foreigners & -0.15 & $-1.65 \dagger$ \\
\hline \multicolumn{3}{|l|}{ Personal initiative } \\
\hline Authoritarianism & -0.23 & $-2.09 *$ \\
\hline Rejection of foreigners & -0.11 & -1.30 \\
\hline \multicolumn{3}{|l|}{ Passivity } \\
\hline Authoritarianism & 0.36 & $3.21 * *$ \\
\hline Rejection of foreigners & 0.03 & 0.34 \\
\hline \multicolumn{3}{|l|}{ Power distance } \\
\hline Authoritarianism & 0.31 & $2.92 * *$ \\
\hline Rejection of foreigners & -0.09 & -1.16 \\
\hline \multicolumn{3}{|l|}{ Control rejection } \\
\hline Authoritarianism & 0.43 & $3.91 * *$ \\
\hline Rejection of foreigners & 0.07 & 0.95 \\
\hline \multicolumn{3}{|l|}{ Aspirations for participation } \\
\hline Authoritarianism & -0.23 & $-1.66 \dagger$ \\
\hline Rejection of foreigners & -0.23 & $-2.02^{*}$ \\
\hline \multicolumn{3}{|l|}{ Higher-order need strength } \\
\hline Authoritarianism & 0.02 & 0.21 \\
\hline Rejection of foreigners & -0.25 & $-3.03 * *$ \\
\hline
\end{tabular}


Table 3 (Continued)

\begin{tabular}{lcc}
\hline \multicolumn{1}{c}{ Dependent variable } & Standard $\beta$ & $t$ value \\
\hline Rejection of woman's right to work & & \\
Authoritarianism & 0.28 & $2.53^{*}$ \\
Rejection of foreigners & 0.10 & 1.10 \\
Error risk taking & & \\
Authoritarianism & 0.09 & 0.83 \\
Rejection of foreigners & -0.17 & $-1.92 \dagger \dagger$ \\
\hline
\end{tabular}

anterest in work innovation and attempts at innovation were tested simultaneously in one model.

$\dagger p<.10 . \dagger \dagger p=.08 .{ }^{*} p<.05 .{ }^{* *} p<.01$.

uncertainty had a significant beta, which showed a negative relationship between authoritarianism and job uncertainty. The squared multiple correlation (SMC) of the dependent variables in the spuriousness model (cf. Table 2), presenting the effect of the third variables, showed that the third variables accounted for $9 \%$ to $34 \%$ of variance in the dependent variables.

\section{Discussion}

This study examined conservatism in the domain of work. Using Wilson's (1973) concept of intolerance of uncertainty, we found conservatism to be related to several work-related attitudes and to personal initiative: Conservatives are reluctant to take responsibility and show less personal initiative at work. They are less ready to change at work, less interested in work innovation, make fewer attempts to introduce innovations at work, show less active career planning, and they are less oriented toward growth and challenge. Conservatives prefer a traditional hierarchical social structure at work, and they reject working women. Thus, most of our hypotheses on conservatism reflecting an anti-change orientation at work were confirmed.

We controlled for three sets of social-context variables and individual-difference variables that could produce spurious relationships: social background (age, gender, education, and SES), negative affectivity, and environmental factors representing high uncertainty at work. The third variables proved to have strong effects. This confirms that controlling for context and individual-difference variables is crucial when studying a construct such as conservatism.

We think that motivational dynamics such as those described by Wilson's (1973) intolerance of uncertainty can best account for the results. However, other theories might be relevant as well. A concept similar to conservatism is dogmatism (Rokeach, 1960). Dogmatism is based on a general intolerance of ambiguity, 
which can alternatively account for the results without changing any of their implications. A further interpretation would relate to the theory of the authoritarian personality (Adorno et al., 1950). Adorno et al. explained authoritarianism and its related attitudes and beliefs with ego-defensive mechanisms that protect the individual from unacceptable internal impulses. The origin of ego-defensive mechanisms is seen in childhood, attributed primarily to experiences with authorities, such as parents. This psychodynamic approach had been very fruitful in research on social and political attitudes, and it can, in many ways, also be applied to our research. However, we found it difficult to draw on psychodynamic mechanisms to explain some of the results of this study. For example, egodefensive mechanisms would not explain why conservatives were less innovative and showed less personal initiative. Wilson also named parental behavior as one precursor to conservatism, but he made intolerance of uncertainty the central psychological antecedent to conservatism. We find this to be the more parsimonious explanation in comparison to a psychodynamic approach.

Furthermore, the investigated relationships can be seen as part of a consistent set of values, attitudes, and beliefs. Conservatism was found to be related to more general values for structure and predictability (Feather 1977, 1984), which is reflected in respective attitudes and behaviors at work. But, according to Feather (1985), a system of values and beliefs is "itself grounded in basic motivational and affective concerns" (p. 885). This implies that explaining the results in terms of a consistent value-belief-attitude system could bring us to a motivational approach, as proposed here.

One new approach taken to explain what holds authoritarianism and numerous attitudes and values together was taken by Altemeyer (1981). He suggested that social learning theory is the basic mechanism, but he also concluded that fear of social chaos plays an important role in authoritarianism (Altemeyer, 1988), which is again not far from Wilson's (1973) theory.

Our hypothesis on rejection of new technology and on error risk taking was not confirmed. Rejection of new technology was operationalized here as opposition to computers. As the use of computers has become relatively widespread in the last decade, most people have had opportunities to get acquainted with them. Therefore, the key word computer might be associated with less novelty, change, and uncertainty than was expected, thereby no longer being threatening to conservative people. With regard to error risk taking, we found negative affectivity to be an important explanatory factor: Being reluctant to risk errors is an effect of negative affectivity, rather than of conservatism.

One shortcoming of our study relates to the number of participants. For the first measurement model, which analyzed all concepts, the ratio of participants to variables was not optimal. Thus, the factor structure as ascertained here might emerge somewhat differently in another sample. However, this does not question the results and implications of our study. If, for example, constructs that 
were highly related in this study (readiness to change at work and interest in innovation) were better presented as a single latent construct, the resulting single construct would most likely have been nonetheless negatively related to conservatism.

This study went beyond previous research in two important ways. The meaning of conservatism was investigated in the domain of work, for which only little research exists to date. Furthermore, in previous studies, conservatism was predominantly related to cognitions. However, we included a performance measure: personal initiative. Our central result is that conservative people do not only differ with regard to their attitudes toward work, but conservatives actually perform differently; that is, they show less personal initiative than do people who are less conservative.

This study was carried out in East Germany. Since the reunification of Germany, radical changes have taken place in East Germany that have deeply affected people's work. However, the practical implications of our results are certainly not limited to formerly socialist countries. The intensity and direction of changes in East Germany are, in many ways, comparable to what other industrialized countries now face because of increased global competition. In the introduction, we pointed out the major changes taking place at work and the new demands associated with these changes. Our results suggest that conservatives will have more problems coping with the increased demand to take responsibility, to be flexible, and to be innovative. Self-development, the continuous increase of competencies and skills, is becoming increasingly important as organizations change from job-based to competency-based structures (Lawler, 1994). The negative relationship of conservatism and higher-order need strength, however, implies that conservatives are not up to it. Additionally, conservatives' lower personal initiative suggests that they are less likely to act successfully in future jobs that will require more independent and self-started actions (Frese, 1997; Howard, 1995).

Our arguments on initiative should not be confused with working hard. Quite the contrary, there are data that show that conservatism is positively related to the Protestant work ethic (Atieh et al., 1987; Feather, 1984). Conservatives may work very hard or even harder than the average worker with regard to their inrole behavior (or task performance). However, working hard may not be the major issue in future work, and might not compensate for a lack of initiative.

With our results on personal initiative, we provide the first evidence that conservative people exhibit different work behaviors than do those who are less conservative. As sufficient knowledge has been accumulated on conservatism and work-related attitudes, future research should focus more on behavior and performance. Further investigation on conservatives' reactions (emotional or behavioral) to the work characteristics that they reject may be useful. For example, do conservatives react differently to increases in decision latitude, compared to less conservative people? Investigating this within a more cognitively oriented framework would also allow interventions to be developed. 


\section{References}

Adorno, T., Frenkel-Brunswik, E., Levinson, D., \& Sandford, R. (1950). The authoritarian personality. New York, NY: Harper \& Row.

Altemeyer, B. (1981). Right-wing authoritarianism. Winnipeg, Canada: University of Manitoba Press.

Altemeyer, B. (1988). Enemies of freedom: Understanding right-wing authoritarianism. San Francisco, CA: Jossey-Bass.

Anderson, J. C., \& Gerbing, D. W. (1988). Structural equation modeling in practice: A review and recommended two-step approach. Psychological Bulletin, 103, 411-423.

Atieh, J. M., Brief, A. P., \& Vollrath, D. A. (1987). The Protestant work ethic conservatism paradox: Beliefs and values in work and life. Personality and Individual Differences, 8, 577-580.

Bahr, H. M., \& Chadwick, B. A. (1974). Conservatism, racial intolerance, and attitudes toward racial assimilation among Whites and American Indians. Journal of Social Psychology, 94, 45-56.

Bollen, K. A. (1989). Structural equations with latent variables. New York, NY: John Wiley \& Sons.

Browne, M. W., \& Cudeck, R. (1993). Alternative ways of assessing model fit. In K. A. Bollen \& J. S. Long (Eds.), Testing structural equation models (pp. 136-162). Newbury Park, CA: Sage.

Der Spiegel. (1991). Zurück an den Herd? Das Profil der Deutschen--was sie vereint, was sie trennt [Back to the kitchen stove? German's profile-similarities and differences]. Spiegel-Spezial, 1, 62-66.

Eysenck, H. J. (1971). Social attitudes and social class. British Journal of Clinical Psychology, 10, 201-212.

Feather, N. T. (1977). Value importance, conservatism, and age. European Journal of Social Psychology, 7, 241-245.

Feather, N. T. (1984). Protestant ethic, conservatism, and values. Journal of Personality and Social Psychology, 46, 1132-1141.

Feather, N. T. (1985). Attitudes, values, and attributions: Explanations of unemployment. Journal of Personality and Social Psychology, 48, 876-889.

Frese, M. (1984). Do workers want control at work or don't they: Some results on denial and adjustment (IfHA-Berichte, No. 5). Berlin, Germany: Institut für Humanwissenschaft in Arbeit und Ausbildung der Technischen Universität.

Frese, M. (1997). Dynamic self-reliance: An important concept for work in the twenty-first century. In C. L. Cooper \& S. E. Jackson (Eds.), Creating tomorrow's organizations (pp. 399-416). Chichester, UK: John Wiley \& Sons.

Frese, M., Fay, D., Hilburger, T., Leng, K., \& Tag, A. (1997). The concept of personal initiative: Operationalization, reliability, and validity in two German samples. Journal of Occupational and Organizational Psychology, 70, 139-161. 
Frese, M., Kring, W., Soose, A., \& Zempel, J. (1996). Personal initiative at work: Differences between East and West Germany. Academy of Management Journal, 39, 37-63.

Frese, M., \& Plüddemann, K. (1993). Umstellungsbereitschaft im Osten und Westen Deutschlands [Readiness to change in East and West Germany]. Zeitschrift für Sozialpsychologie, 24, 198-210.

Gillies, J., \& Campbell, S. (1985). Conservatism and poetry preferences. British Journal of Social Psychology, 24, 223-227.

Glasgow, M. R., \& Cartier, A. M. (1985). Conservatism, sensation-seeking, and music preferences. Personality and Individual Differences, 6, 393-395.

Hall, D. T., \& Mirvis, P. H. (1995). Careers as lifelong learning. In A. Howard (Ed.), The changing nature of work (pp. 323-361). San Francisco, CA: Jossey-Bass.

Hofstede, G. (1991). Cultures and organizations: Software of the mind. London, UK: McGraw-Hill.

Howard, A. (1995). A framework for work change. In A. Howard (Ed.), The changing nature of work (pp. 3-44). San Francisco, CA: Jossey-Bass.

Hoyle, R. H., \& Panter, A. (1995). Writing about structural equation models. In R. H. Hoyle (Ed.), Structural equation modeling (pp. 158-176). Thousand Oaks, CA: Sage.

Kieler Diskussionsbeiträge. (1991). Gesamtwirtschaftliche und unternehmerische Anpassungsprozesse in Ostdeutschland [Economic and business-related adaptation processes in East Germany]. Kiel, Germany: Institut für Weltwirtschaft.

Kohn, M. L., \& Schooler, C. (1983). Work and personality: An inquiry into the impact of social stratification. Norwood, NJ: Ablex.

Lawler, E. E. (1994). From job-based to competency-based organizations. Journal of Organizational Behavior, 15, 3-15.

Lederer, G. (1983). Jugend und Autorität [Youth and authority]. Opladen, Germany: Westdeutscher Verlag.

McAllister, P., \& Anderson, A. (1991). Conservatism and the comprehension of implausible texts. European Journal of Social Psychology, 21, 147-164.

McFarland, S. G., Ageyev, V. S., \& Abalakina-Paap, M. A. (1992). Authoritarianism in the former Soviet Union. Journal of Personality and Social Psychology, 63, 1004-1010.

Patchen, M. (1965). Some questionnaire measures of employee motivation and morale. Ann Arbor, MI: Institute for Social Research.

Ray, J. J. (1973). Conservatism, authoritarianism, and related variables: A review and empirical study. In G. D. Wilson (Ed.), The psychology of conservatism (pp. 17-35). London, UK: Academic.

Ray, J. J., \& Wilson, R. S. (1976). Social conservatism in Australia. Australian and New Zealand Journal of Sociology, 12, 254-257.

Rokeach, M. (1960). The open and closed mind: Investigations into the nature of belief systems and personality systems. New York, NY: Basic Books. 
Rokeach, M. (1973). The nature of human values. New York, NY: Free Press.

Rybowiak, V., Garst, H., Frese, M., \& Batinic, B. (1999). Error orientation questionnaire (EOQ): Reliability, validity, and different language equivalence. Journal of Organizational Behavior, 20, 527-547.

Sales, S. M. (1973). Threat as a factor in authoritarianism: An analysis of archival data. Journal of Personality and Social Psychology, 28, 44-57.

Schaubroeck, J., Ganster, D. C., \& Fox, M. L. (1992). Dispositional affect and work-related stress. Journal of Applied Psychology, 77, 322-335.

Schiebel, B., Riemann, R., \& Mummendey, H. D. (1984). Eine aktualisierte deutschsprachige Form der Konservatismusskala von Wilson \& Patterson [Actualized German version of the Wilson-Patterson Conservatism scale]. Zeitschrift für Differentielle und Diagnostische Psychologie, 5, 311-321.

Tetlock, P. E. (1984). Cognitive style and political belief systems in the British House of Commons. Journal of Personality and Social Psychology, 46, 365375.

Tetlock, P. E., Bernzweig, J., \& Gallant, J. (1985). Supreme Court decision making: Cognitive style as a predictor of ideological consistency of voting. Journal of Personality and Social Psychology, 48, 1227-1239.

Truett, K. R. (1993). Age differences in conservatism. Personality and Individual Differences, 14, 405-411.

Waller, J. (1993). Correlation of need for cognition and modern racism. Psychological Reports, 73, 542.

Warr, P. B., Cook, J., \& Wall, T. D. (1979). Scales for the measurement of some work attitudes and aspects of psychological well-being. Journal of Occupational Psychology, 52, 129-148.

Watson, D., Clark, L. A., \& Tellegen, A. (1988). Development and validation of brief measures of positive and negative affect: The PANAS scales. Journal of Personality and Social Psychology, 54, 1063-1070.

Wilson, G. D. (1973). The psychology of conservatism. New York, NY: Academic Press.

Wilson, G. D., Ausman, J., \& Mathews, T. R. (1973). Conservatism and art preferences. Journal of Personality and Social Psychology, 25, 286-288.

Wilson, G. D., \& Patterson, J. R. (1968). A new measure of conservatism. British Journal of Social and Clinical Psychology, 7, 264-269.

Wittke, V., Voskamp, U., \& Bluhm, K. (1993). Den Westen überholen, ohne ihn einzuholen? [Overtaking the West-but not catching up?] In R. Schmidt (Ed.), Zwischenbilanz: Analysen zum Transformationsprozess der ostdeutschen Industrie (pp. 131-154). Berlin, Germany: Akademie Verlag.

Zapf, D. (1991). Stressbezogene Arbeitsanalyse bei der Arbeit mit unterschiedlichen Bürosoftwaresystemen [Stress-related job analysis of work with various office software systems]. Zeitschrift für Arbeits- und Organisationspsychologie, 35, 2-14. 